\title{
Barriers and the facilitator of whole grain consumption in Northern Ireland
}

\author{
E. McMackin ${ }^{1}$, M. C. McKinley ${ }^{1}$ and M. Dean ${ }^{2}$ \\ ${ }^{1}$ School of Medicine, Dentistry and Biomedical Sciences and ${ }^{2}$ School of Biological Sciences, Queen's University, \\ Belfast BT7 INN, UK
}

Many studies have demonstrated positive associations between high whole grain intakes and the risk of CHD, obesity, type- 2 diabetes and certain cancers $^{(1)}$. Health claims in the UK relating to CHD have been endorsed for use on foods with at least $51 \%$ whole grain ${ }^{(2)}$. Despite the recognized health benefits, whole grain intakes in the UK are extremely low, with the number of non-consumers being approximately $29 \%$ in $2000-2001^{(3)}$, and only $5 \%$ meeting USA's dietary recommendation of three $16 \mathrm{~g}$ servings daily ${ }^{(4)}$. It is therefore important to understand the reasons for such low intakes amongst UK consumers in order to help devise appropriate educational strategies to help increase consumption. Till date, only a small number of studies have been published in this area, and only one study has encompassed a broad range of sub-groups from the UK population, as well as other EU countries ${ }^{(5)}$; however, this study did not include Northern Ireland. Therefore, the aim of this study was to use a qualitative, focus group approach to identify the barriers and facilitators of whole grain consumption in Northern Ireland.

Ethical approval for the study was obtained from Queen's University, Belfast's School of Biological Sciences Ethical Committee. Focus groups were conducted according to a focus group schedule that had been piloted and refined. All focus groups were conducted by one facilitator (EMcM), they were audio-recorded and transcribed verbatim, and the data were analysed using a thematic analysis approach $^{(6)}$ in conjunction with QSR NVivo 8 software (QSR International Pty, Ltd, Doncaster, Victoria, Australia).

In total, seven focus groups were completed with 43 adults aged over 18 years from urban and rural areas throughout Northern Ireland. Participants had to be at least partly responsible for food shopping. The key barriers to whole grain consumption were related to the sensory characteristics of whole grains (taste, texture and appearance) (e.g. 'Like not very tasty .... Its anything that's good for you, you know, it's just not going to appeal'), knowledge about what constitutes a whole grain, how to identify these foods and how to cook them (e.g. 'I don't really know an awful lot about it'), and cost issues as whole grains were perceived to cost more than refined grains (e.g. 'I know it's dearer than everything else').

Key facilitators to whole grain consumption were sensory characteristics and health concerns. While sensory characteristics were a barrier for many, they were also seen as a positive factor for some people who highlighted that they preferred the taste, texture and appearance of whole grain foods to refined alternatives (e.g. 'I would live on wheaten bread or toast. I mean I could eat that 3 times a day. I love it'). Many people stated that the chose whole grains because they wanted to do their best for their children (e.g. 'I want to keep my kids healthy so they will grow up well and I also want to teach them the importance of eating well and looking after their health'), because they thought they may alleviate certain medical conditions (e.g. 'I started eating whole meal bread because my cholesterol levels were too high') and because of an overall level of health consciousness (e.g. 'I would tend to buy things that I think are healthy').

This research highlights a number of barriers that should be prioritised in nutrition education activities in this area and also presents a challenge to the food industry in terms of making whole grain foods more acceptable and appealing to the consumer. Further research in specific population sub-groups such as individuals of low economic status and from different ethnic groups would provide further insight into some of these issues.

1 Slavin JL (2004) Nutr Res Rev 17, 99-110.

2 Richardson DP (2003) Proc Nutr Soc 62, 161-169.

3 Thane CW, Jones AM, Stephen AM et al. (2007) Br J Nutr 97, 987-992.

4 Lang R, Thane CW, Bolton-Smith C et al. (2003) Publ Health Nutr 6, 479-484.

5 Arvola A, Lähteenmäki L, Dean M et al. (2007) J Cereal Sci 46, 197-206.

6 Boyatziz RE (1998) Transforming Qualitative Information: Thematic Analysis and Code Development. Sage, USA. 